\title{
Haemodynamic Effects of Nitroglycerin in Patients with Mitral Valvular Disease
}

\author{
B. CHRISTENSSON, A. GUSTAFSON, H. WESTLING, AND G. WIGAND \\ From the Departments of Cardiology and Clinical Physiology, Lasarettet, Lund, Sweden
}

Nitrites are widely used for the treatment of angina pectoris, but their mechanism of action is still not clear. Animal experiments have shown that nitrites dilate arteries, arterioles, capillaries, and veins (for a review: see Charlier, 1961). Most workers feel that nitroglycerin acts by dilating coronary vessels, though such an effect has been difficult to show in patients with coronary heart disease. Moreover, Gorlin et al. (1959), Weiss, Wilkins, and Haynes (1937), Wilkins, Haynes, and Weiss (1937), and Johnsson, Henning, and Åblad (1965) have shown that the most important circulatory effect of nitrites in man is probably a dilatation of peripheral veins, which may lead to a fall in central blood volume and a reduction of the work of the heart. Others, e.g. Christensson, Karlefors, and Westling (1965), maintain that this may be a sufficient explanation for the relief of anginal pain, since they found a reduced stroke volume after nitroglycerin, particularly when the drug was given during anginal pain provoked by sitting exercise. However, these findings were not confirmed by Hoeschen et al. (1966): they found increased cardiac output and stroke volume when nitroglycerin was given to patients with angina pectoris under experimental conditions which appear similar to those of Christensson et al. (1965). It has also been observed by $O$. Müller (1963, personal communication), Arborelius et al. (1968), and Najmi et al. (1967) that nitroglycerin may prevent anginal pain during supine exercise without a reduction of cardiac output, but with reduced pressures in the lesser circulation. Variations in the patients and the experimental methods may possibly explain the different results, but nevertheless these findings and those of Hoeschen et al. (1966) appear to cast doubt on the theory

Received January 31, 1968. that nitroglycerin acts only by reducing the work of the heart.

New light on the haemodynamic consequences of coronary insufficiency was obtained by Müller and Rørvik (1958). They found that anginal pain was associated with increased pressures in the left atrium and the pulmonary artery. After nitroglycerin the pressures were quickly lowered to normal. The effects of nitroglycerin and related substances on other conditions with raised pressures in the pulmonary circulation have also been studied. Thus, reduction of pressures in the pulmonary artery and the left atrium has been obtained in patients with left ventricular failure due to hypertension, and in patients with mitral valvular disease (Johnson, Gross, and Hale, 1957; Johnson, Fairley, and Carter, 1959; Fremont, 1961; Kleinerman et al., 1964).

The present report contains further observations on the action of nitroglycerin in patients with mitral valvular disease, with particular reference to the effects during exercise. The investigation was initiated by the favourable clinical effects obtained by nitroglycerin in patients with symptoms of imminent pulmonary oedema in connexion with catheterization.

\section{SubJeCtS AND METHOdS}

Observations were made on 26 patients with mitral valvular disease, judged to be predominantly stenosis, who underwent a routine pre-operative assessment.

Right heart catheterization was carried out in the supine position, after premedication with a small dose of barbiturate; the examination was performed in the morning and the patients were not given breakfast.

A double-lumen catheter was used for simultaneous recording of pressures in the pulmonary artery and in the wedge position (PCV pressure). A polyethylene 
TABLE I

HAEMODYNAMIC OBSERVATIONS IN 12 PATIENTS WITH MITRAL VALVULAR DISEASE AND SINUS RHYTHM DURING CONTINUOUS WORK IN SUPINE POSITION BEFORE AND AFTER ADMINISTRATION OF 0.5 MG. NITROGLYCERIN SUBLINGUALLY

\begin{tabular}{|c|c|c|c|c|c|c|c|c|c|c|c|c|c|c|c|}
\hline \multirow{3}{*}{ Sex } & \multirow{3}{*}{$\begin{array}{l}\text { Age } \\
\text { (yr.) }\end{array}$} & \multirow{3}{*}{$\begin{array}{c}\text { Heart rate } \\
\text { (beats/min.) }\end{array}$} & \multirow{2}{*}{\multicolumn{2}{|c|}{$\begin{array}{c}\text { Cardiac } \\
\text { output } \\
\text { (1./min.) }\end{array}$}} & \multirow{2}{*}{\multicolumn{2}{|c|}{$\begin{array}{c}\text { Stroke } \\
\text { volume } \\
\text { (ml.) }\end{array}$}} & \multicolumn{7}{|c|}{ Pressures (mm.Hg) } & \multirow{3}{*}{$\begin{array}{c}\text { Oxygen } \\
\text { consumption } \\
\text { (ml./min.) }\end{array}$} & \multirow{3}{*}{$\begin{array}{l}\text { Art. ven. } \\
\text { oxygen diff. } \\
\text { (ml./l.) }\end{array}$} \\
\hline & & & & & & & \multirow{2}{*}{$\frac{\mathrm{PCV}}{\mathrm{M}}$} & \multicolumn{3}{|c|}{ Pulm. art. } & \multicolumn{3}{|c|}{ Brach. art. } & & \\
\hline & & & BSP & Fick & BSP & Fick & & $\mathbf{S}$ & $\mathbf{D}$ & $\mathbf{M}$ & $\mathbf{S}$ & $\mathrm{D}$ & $\mathrm{M}$ & & \\
\hline $\begin{array}{l}\text { F } \\
\text { F } \\
\text { F } \\
\text { F } \\
\text { F } \\
\text { F } \\
\text { F } \\
M \\
M \\
M \\
M\end{array}$ & $\begin{array}{l}\frac{51}{57} \\
\frac{44}{43} \\
\frac{58}{52} \\
\frac{51}{58} \\
\frac{58}{54} \\
\frac{49}{49}\end{array}$ & $\begin{array}{cr}\text { B } & 159 \\
\text { A } & 163 \\
\text { B } & 101 \\
\text { A } & 109 \\
\text { B } & 107 \\
\text { A } & 111 \\
\text { B } & 105 \\
\text { A } & 110 \\
\text { B } & 142 \\
\text { A } & 152 \\
\text { B } & 118 \\
\text { A } & 127 \\
\text { B } & 121 \\
\text { A } & 136 \\
\text { B } & 134 \\
\text { A } & 134 \\
\text { B } & 90 \\
\text { A } & 95 \\
\text { B } & 91 \\
\text { A } & 95 \\
\text { B } & 93 \\
\text { A } & 99 \\
\text { B } & 100 \\
\text { A } & 104\end{array}$ & $\begin{array}{r}5 \cdot 4 \\
5 \cdot 0 \\
7 \cdot 3 \\
6 \cdot 1 \\
9 \cdot 0 \\
8 \cdot 8 \\
9 \cdot 2 \\
8 \cdot 0 \\
9 \cdot 5 \\
9 \cdot 3 \\
7 \cdot 9 \\
8 \cdot 4 \\
8 \cdot 4 \\
7 \cdot 9 \\
9 \cdot 4 \\
8 \cdot 2 \\
10 \cdot 0 \\
7 \cdot 7 \\
10 \cdot 7 \\
11 \cdot 2 \\
10 \cdot 8 \\
10 \cdot 8 \\
8 \cdot 9 \\
7 \cdot 4\end{array}$ & $\begin{array}{c}\text { 二 } \\
\text { 二 } \\
\overline{8 \cdot 2} \\
8 \cdot 4 \\
10 \cdot 1 \\
8 \cdot 0 \\
12 \cdot 8 \\
10 \cdot 1 \\
9 \cdot 1 \\
9 \cdot 8 \\
= \\
\overline{9} \cdot 6 \\
9 \cdot 0 \\
9 \cdot 6 \\
9 \cdot 6 \\
9 \cdot 4 \\
10 \cdot 2 \\
10.9 \\
10 \cdot 4 \\
10 \cdot 7 \\
8.5\end{array}$ & $\begin{array}{r}34 \\
31 \\
72 \\
56 \\
84 \\
79 \\
88 \\
73 \\
67 \\
61 \\
67 \\
66 \\
69 \\
55 \\
70 \\
61 \\
111 \\
81 \\
118 \\
118 \\
116 \\
109 \\
89 \\
71\end{array}$ & $\begin{array}{r}\text { 二 } \\
\text { 二 } \\
\overline{77} \\
76 \\
96 \\
73 \\
90 \\
66 \\
77 \\
77 \\
\overline{-} \\
77 \\
67 \\
107 \\
101 \\
103 \\
107 \\
117 \\
105 \\
167 \\
82\end{array}$ & $\begin{array}{l}37 \\
21 \\
15 \\
9 \\
34 \\
28 \\
22 \\
13 \\
32 \\
25 \\
32 \\
22 \\
22 \\
13 \\
30 \\
10 \\
22 \\
13 \\
34 \\
23 \\
31 \\
22 \\
39 \\
15\end{array}$ & $\begin{array}{l}76 \\
54 \\
47 \\
32 \\
55 \\
51 \\
62 \\
40 \\
= \\
56 \\
43 \\
= \\
= \\
- \\
55 \\
86 \\
55 \\
81 \\
61 \\
-\end{array}$ & $\begin{array}{l}55 \\
21 \\
20 \\
10 \\
36 \\
27 \\
27 \\
17 \\
= \\
26 \\
20 \\
= \\
= \\
25 \\
15 \\
34 \\
22 \\
35 \\
25 \\
-\end{array}$ & $\begin{array}{l}55 \\
30 \\
30 \\
18 \\
45 \\
38 \\
42 \\
28 \\
43 \\
37 \\
41 \\
22 \\
32 \\
18 \\
42 \\
20 \\
35 \\
23 \\
55 \\
35 \\
52 \\
38 \\
56 \\
29\end{array}$ & $\begin{array}{l}201 \\
178 \\
173 \\
140 \\
169 \\
161 \\
153 \\
147 \\
154 \\
151 \\
150 \\
142 \\
167 \\
170 \\
190 \\
164 \\
152 \\
116 \\
138 \\
130 \\
127 \\
115 \\
153 \\
135\end{array}$ & $\begin{array}{r}105 \\
103 \\
70 \\
63 \\
100 \\
96 \\
83 \\
78 \\
70 \\
73 \\
80 \\
84 \\
95 \\
100 \\
97 \\
85 \\
80 \\
67 \\
67 \\
63 \\
63 \\
57 \\
83 \\
83\end{array}$ & $\begin{array}{r}149 \\
127 \\
108 \\
96 \\
128 \\
119 \\
110 \\
95 \\
105 \\
102 \\
113 \\
107 \\
131 \\
122 \\
144 \\
111 \\
101 \\
91 \\
95 \\
86 \\
86 \\
78 \\
112 \\
103\end{array}$ & $\begin{array}{r}\overline{-} \\
\overline{-} \\
642 \\
644 \\
677 \\
642 \\
779 \\
787 \\
734 \\
786 \\
- \\
854 \\
824 \\
847 \\
860 \\
770 \\
880 \\
970 \\
970 \\
1020 \\
940\end{array}$ & $\begin{array}{r}88 \\
83 \\
72 \\
83 \\
78 \\
77 \\
67 \\
80 \\
61 \\
78 \\
81 \\
80 \\
73 \\
71 \\
89 \\
92 \\
88 \\
90 \\
82 \\
86 \\
89 \\
93 \\
95 \\
110\end{array}$ \\
\hline
\end{tabular}

$P C V=$ Pulmonary artery wedge pressure.

BSP = Bromsulphalein.

$\mathrm{S}, \mathrm{D}, \mathbf{M}=$ Systolic, diastolic, and mean pressure, respectively.

catheter was introduced into the brachial artery percutaneously. Oxygen consumption was measured by collecting expired air in a Douglas bag for 7 minutes at rest and 4 minutes during exercise. Respiratory gases were analysed according to Scholander (1947). Cardiac output was measured by the Fick principle and also by the dye-dilution technique, using bromsulphalein (BSP) as an indicator (Wassén, 1956). Both methods were used simultaneously when possible.

Pressures were measured by inductance or capacitance manometers and recorded together with the electrocardiogram on an ink-writing electrocardiogram. *

Examinations were carried out on 6 patients with sinus rhythm and 8 with atrial fibrillation at rest. Cardiac output and pressures were determined, and immediately after this $0.5 \mathrm{mg}$. nitroglycerin was given sublingually. New determinations were made 3 to 5 minutes after the tablet had dissolved.

Exercise tests were carried out on 12 patients in sinus rhythm (Table I). The supine patient pedalled an electrically-braked bicycle ergometer, $\dagger$ with a centre of rotation approximately at heart level. The work load was $300 \mathrm{kpm}$./min. for men and $200 \mathrm{kpm}$./min. for women. The patients exercised for $10-15$ minutes. The first haemodynamic measurements were carried out after about 5 minutes of continuous work. Nitroglycerin was then given while the patient continued working. New determinations of pressures and cardiac output were made 4 to 6 minutes after the nitroglycerin had been given.

* Mingograph, AB Elema, Sweden.

t AB Elema.
$\mathbf{A}=$ After nitroglycerin.
$\mathbf{B}=$ Before nitroglycerin.

In order to evaluate the possible spontaneous changes in the haemodynamic conditions during continuous exercise, duplicate determinations were made in a series of patients with mitral valvular disease (Gustafson, 1966). The interval between the two determinations was about 5 minutes. The results in 14 patients with sinus rhythm are given in Table II.

\section{Results}

The predominant haemodynamic effect of nitroglycerin during exercise was the reduction of both pulmonary and PCV pressures (Tables I and II). The reduction of systemic arterial pressure was also statistically significant. Cardiac output was slightly decreased in those patients to whom nitroglycerin was given in comparison with the patients to whom it was not given. The stroke volume was more reduced since the heart rate increased after nitroglycerin. The arteriovenous oxygen difference increased slightly.

A difference in the behaviour of the cardiac output and stroke volume became apparent if the patients were divided in two groups, according to the level of the PCV pressure after nitroglycerin. In the 6 patients with the lowest PCV pressures after nitroglycerin (average value $12 \mathrm{~mm}$. $\mathrm{Hg}$ against $25 \mathrm{~mm}$. Hg before the drug), cardiac output decreased by $1.31 . / \mathrm{min}$. and stroke volume by $17 \mathrm{ml}$., on the average. In the remaining 6 patients PCV pressures fell from 33 to $25 \mathrm{~mm}$. $\mathrm{Hg}$. In this group 
TABLE II

SUMMARY OF HAEMODYNAMIC EFFECTS OF NITROGLYCERIN DURING EXERCISE IN PATIENTS WITH MITRAL VALVULAR DISEASE (SINUS RHYTHM)

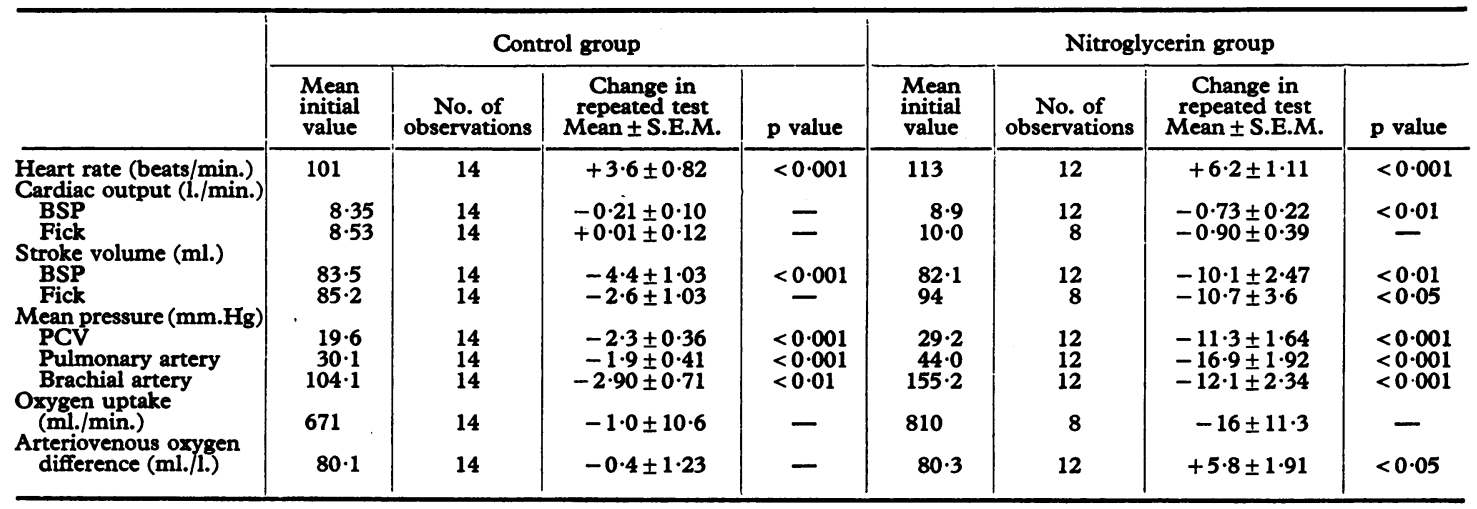

cardiac output was unchanged and the average stroke volume fell by $3.7 \mathrm{ml}$. only.

The haemodynamic changes after nitroglycerin at rest were in principle the same as those described above during exercise. ${ }^{\star}$

In 7 patients, who had respiratory distress and objective signs of imminent pulmonary oedema at rest or during exercise, the symptoms disappeared quickly after nitroglycerin, in pace with the reduction of PCV pressure.

\section{Discussion}

The effects of nitroglycerin in the present series of patients with mitral valvular disease were in the main confined to a reduction of pulmonaryarterial and PCV pressures. The calculated pulmonary vascular resistance was reduced more than the systemic vascular resistance. These observations are in accordance with those reported by Dresdale et al. (1963) regarding the effect of isosorbide dinitrate on the haemodynamics in patients with mitral stenosis.

One possible mode of action of nitroglycerin in mitral stenosis is on the peripheral veins (capacitance vessels), thereby reducing the blood flow into the lesser circulation, with a consequent drop in pulmonary and left atrial pressure. It is also possible that nitroglycerin reduces the tone in the pulmonary veins; this would also decrease the left atrial pressure. The latter mechanism would fit in with the reports of disturbed ventilation, decreased compli-

\footnotetext{
^The results of these measurements are not given here, but the authors will be pleased to send them to anyone who is interested.
}

ance, and increased pulmonary blood volume (Dresdale et al., 1963; Kleinerman et al., 1964; Ferrer et al., 1966).

It seems likely that the pressure gradient over the mitral valve was reasonably well maintained in those patients in whom nitroglycerin caused a moderate fall in PCV pressure. Left ventricular diastolic pressure would thus decrease in parallel with the left atrial pressure. With a more pronounced effect, stroke volume and cardiac output also fell, indicating a reduction in effective pressure gradient, possible because of approaching a "minimal" left ventricular diastolic pressure.

We would like to suggest that the mechanism of action of nitroglycerin is the same in mitral valvular disease and in coronary heart disease. The different results as regards cardiac output and stroke volume obtained by O. Müller (1963, personal communication), Christensson et al. (1965), Hoeschen et al. (1966), Arborelius et al. (1968), and Najmi et al. (1967) should, in our opinion, be regarded as quantitatively rather than qualitatively different.

In this connexion, the important problem of a generally increased venous tone in patients with manifest or imminent cardiac failure should be discussed. It is even possible that the increase in venous tone in certain patients is more pronounced in the pulmonary veins. Raphael and Steiner (1966) have shown that the motor activity of the pulmonary veins is changed in patients with mitral stenosis. It is well known that an increase in venous tone caused by sympathetic stimulation can bring about pulmonary oedema in such patients, as well as in patients with latent left ventricular failure from any cause. In such patients the administra- 
tion of nitrites can be said to interfere with an important patho-physiological "trigger" mechanism. A similar mechanism may well operate in attacks of angina pectoris, particularly those caused by "emotional tension".

Dresdale et al. (1963) concluded:" The impression is that the nitrates have an effect on the pulmonary vascular bed when there is pulmonary hypertension secondary to increased pulmonary venous pressure." Our investigations support this statement as regards the effect of nitroglycerin at rest, and supplement the previous observations by measurements during exercise, which show in principle the same effect.

An important stimulus for the present work was the repeated clinical observation that the administration of nitroglycerin to patients with imminent pulmonary oedema from any cause, including mitral valvular disease, had a good effect on the subjective symptoms and also produced an objective improvement, with disappearance of physical signs. This effect has been obtained not only during heart catheterization but also during long-continued treatment at home.

\section{SUMMARY}

The haemodynamic response to nitroglycerin sublingually was examined at rest or during exercise in patients with mitral valvular disease. Six patients with sinus rhythm and 8 patients with atrial fibrillation were studied at rest, and 12 patients with sinus rhythm were studied during exercise.

The dominant finding was a reduction in pulmonary arterial and pulmonary artery wedge pressures. At the same time, subjective and objective symptoms of pulmonary engorgement were reduced in 7 patients.

The study was aided by a grant from the Swedish National Association Against Heart and Lung Diseases.

\section{REFERENCES}

Arborelius, M., Jr., Lecerof, H., Malm, A., and Malmborg, R. O. (1968). Acute effect of nitroglycerin on haemodynamics of angina pectoris. Brit. Heart f., 30, 407.

Charlier, R. (1961). Coronary Vasodilators. Pergamon Press, Oxford.

Christensson, B., Karlefors, T., and Westling, H. (1965). Haemodynamic effects of nitroglycerin in patients with coronary heart disease. Brit. Heart f., 27, 511.
Dresdale, D. T., Yuceoglu, Y. Z., Reyes, A., Lunger, M., and Nassar, A. M. (1963). Hemodynamic effects of isosorbide dinitrate in patients with rheumatic heart disease and pulmonary hypertension. Angiology, 14, 349.

Ferrer, M. I., Bradley, S. E., Wheeler, H. O., Enson, Y., Preisig, R., Brickner, P. W., Conroy, R. J., and Harvey, R. M. (1966). Some effects of nitroglycerin upon the splanchnic, pulmonary, and systemic circulations. Circulation, 33, 357.

Fremont, R. E. (1961). The actions of organic nitrates on the cardiopulmonary and peripheral circulations. Angiology, 12, 391.

Gorlin, R., Brachfeld, N., MacLeod, C., and Bopp, P. (1959). Effects of nitroglycerin on the coronary circulation in patients with coronary artery disease or increased left ventricular work. Circulation, 19, 705.

Gustafson, A. (1966). Ultrasoundcardiography in mitral stenosis. Acta med. scand., Suppl. 461.

Hoeschen, R. J., Bousvaros, G. A., Klassen, G. A., Fam, W. M., and McGregor, M. (1966). Haemodynamic effects of angina pectoris, and of nitroglycerin in normal and anginal subjects. Brit. Heart f., 28, 221.

Johnson, J. B., Fairley, A., and Carter, C. (1959). Effects of sublingual nitroglycerin on pulmonary arterial pressure in patients with left ventricular failure. Ann. intern. Med., 50, 34.

- Gross, J. F., and Hale, E. (1957). Effects of sublingual administration of nitroglycerin on pulmonary-artery pressure in patients with failure of the left ventricle. New Engl. F. Med., 257, 1114.

Johnsson, G., Henning, M., and Åblad, B. (1965). Rate of onset of vasodilator effect of glyceryl trinitrate, propatylnitrate and erythrityl tetranitrate in man. Scand $\mathcal{F}$. clin. Lab. Invest., 17, 600 .

Kleinerman, L., Ghita, M., Bandu, I., and Roseteanu, G. (1964). Vascular reactivity in lesser circulation in pulmonary hypertension. IVth European Congress of Cardiology, Prague. Abstracts, p. 173.

Müller, O., and Rørvik, K. (1958). Haemodynamic consequences of coronary heart disease. With observations during anginal pain and on the effect of nitroglycerin. Brit. Heart f., 20, 302.

Najmi, M., Griggs, D. M., Kasparian, H., and Novack, P. (1967). Effects of nitroglycerin on hemodynamics during rest and exercise in patients with coronary insufficiency. Circulation, 35, 46.

Raphael, M. J., and Steiner, R. E. (1966). Selective cinefluoroscopic studies of pulmonary circulatory disorders. Brit. Heart f., 28, 523.

Scholander, P. F. (1947). Analyzer for accurate estimation of respiratory gases in one-half cubic centimeter samples. f. biol. Chem., 167, 235.

Wassén, A. (1956). The use of bromsulphalein for determination of the cardiac output. Scand. F. clin. Lab. Invest., 8, 189.

Weiss, S., Wilkins, R. W., and Haynes, F. W. (1937). The nature of circulatory collapse induced by sodium nitrite. 7. clin. Invest., 16, 73.

Wilkins, R. W., Haynes, F. W., and Weiss, S. (1937). The rôle of the venous system in circulatory collapse induced by sodium nitrite. $\mathcal{F}$. clin. Invest., 16, 85 . 